\title{
To Enhance Collaborative Learning and Practice Network Knowledge with a Virtualization Laboratory and Online Synchronous Discussion
}

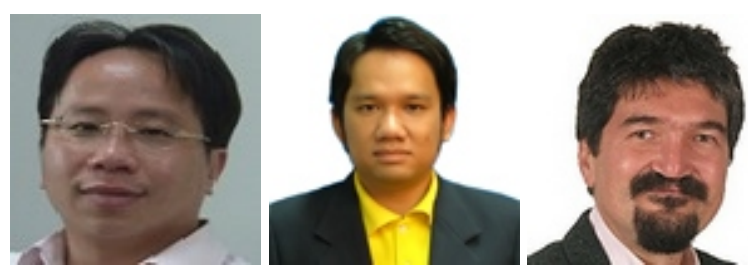

Wu-Yuin Hwang ${ }^{1}$, Chaknarin Kongcharoen ${ }^{1}$, and Gheorghita Ghinea ${ }^{2}$ ${ }^{1}$ National Central University, Taiwan, Province of China, ${ }^{2}$ Brunel University, United Kingdom

\section{Abstract}

Recently, various computer networking courses have included additional laboratory classes in order to enhance students' learning achievement. However, these classes need to establish a suitable laboratory where each student can connect network devices to configure and test functions within different network topologies. In this case, the Linux operating system can be used to operate network devices and the virtualization technique can include multiple OSs for supporting a significant number of students. In previous research, the virtualization application was successfully applied in a laboratory, but focused only on individual assignments. The present study extends previous research by designing the Networking Virtualization-Based Laboratory (NVBLab), which requires collaborative learning among the experimental students. The students were divided into an experimental group and a control group for the experiment. The experimental group performed their laboratory assignments using NVBLab, whereas the control group completed them on virtual machines (VMs) that were installed on their personal computers. Moreover, students using NVBLab were provided with an online synchronous discussion (OSD) feature that enabled them to communicate with others. The laboratory assignments were divided into two parts: Basic Labs and Advanced Labs. The results show that the experimental group significantly outperformed the control group in two Advanced Labs and the post-test after Advanced Labs. Furthermore, the experimental group's activities were better than those of the control group based on the total average of the command count per laboratory. Finally, the findings of the interviews and questionnaires with the experimental group reveal that NVBLab was helpful during and after laboratory class. 
Keywords: Virtualization-based laboratory; online synchronous discussion; collaborative learning; teaching networking concepts

\section{Introduction}

A computer networking laboratory provides an opportunity for students to learn how to configure and manage network services. In general, a networking laboratory employs real networking devices to perform experiments but, recently, research has also utilized the Linux operating system (OS) for cost efficiency (Nieh \& Vaill, 2005; Sarkar \& Lian, 2003) as well as web-based technologies to establish remote access to all devices (Lahoud \& Tang, 2006; Summers, Bhagyavati, \& Martin, 2005; Wannous \& Nakano, 2010). In particular, virtualization-based technology can be used to install a group of virtual machines (VMs) on one server and run OSs on these VMs, also known as guest OSs. Guest OSs enable VMs to be used as hubs, switches, and routers in laboratory classes. Moreover, laboratories that implement virtualization-based technology allow learners to practice on real laboratory devices (Anisetti et al., 2007; Border, 2007; Wannous \& Nakano, 2010).

The present study extends previous research that only focused on individual laboratory assignments (Wannous \& Nakano, 2010; Wannous, Nakano, Kita, \& Sugitani, 2007) by designing the Networking Virtualization-Based Laboratory (NVBLab). This is based on the online collaborative learning framework (Harasim, 2011), which requires collaborative learning among the students when performing experiments. Further, the purpose of this study is to describe how beneficial the NVBLab is in students' behavior, perception, and learning achievement.

The students were divided into a control group and an experimental group, and one laboratory experiment was conducted for each group. The experimental group performed their laboratory assignments using NVBLab, whereas the control group utilized VMs that were installed on their personal computers (PCs). Moreover, students using NVBLab were provided with an online synchronous discussion (OSD) feature that enabled them to communicate with others as well as their teacher and teaching assistant (TA). This laboratory experiment consisted of Basic Labs (comprising Linux concepts and basic practices) and Advanced Labs (comprising Linux networking and advanced practices). Participants in the control group accomplished all of the assignments in the Basic and Advanced Labs, whereas those in the experimental group completed the assignments in the Basic Labs individually and those in the Advanced Labs as group assignments. 


\section{Related Work}

\section{Theories of Online Collaborative Learning}

Previously, collaborative learning activities have only been provided for on-campus students since the limitations of time and space were barriers for off-campus students, especially in collaborative work (Kimball, 1998). However, the introduction of Internetbased collaborative learning systems offers new opportunities for student collaboration, as well as new challenges for teachers supporting such group work (Watabe, Hamalainen, \& Whinston, 1995). For instance, various schools and universities have increasingly adopted course management systems (CMS) such as Moodle and Blackboard that provide tools for synchronous and asynchronous online communication. By using them, learners can chat/discuss among themselves as well as participate in group activities. These changes have challenged educators to provide more opportunities for collaboration amongst learners. Therefore, computer-based collaborative learning should become an integral part of the educational strategies of online courses (McAlpine, 2006).

Harasim (2011) proposed the online collaborative learning (OCL) theory, which focuses on three components, namely collaborative learning and knowledge building mediated by the Internet for formal and informal education, working together online to identify and solve problems, and the applications of OCL which refer to web-based technologies such as text-based, multimedia, synchronous, and asynchronous tools.

\section{Online Synchronous Discussion (OSD)}

Recently, OSD capabilities have been provided in a wide range of educational activities. Several studies have illustrated the learning benefits of using OSD. For example, researchers have indicated that the verbal immediacy made possible by OSD develops logical reasoning and critical thinking (Murphy \& Collins, 1997), that it improves students' interaction and collaboration (Hew \& Cheung, 2003; Kim, 2012; Shana, 2009), and quickly motivates students to achieve the study goal (Kehrwald, 2008). Compared to traditional face-to-face discussions, OSD enables students and teachers to communicate through synchronous text-based messages rather than face-to-face conversations. Also, in a training laboratory, an e-classroom's OSD facilitated effective communication between trainees (Lobel, Swedburg, \& Neubauer, 2002). Therefore, OSD can be beneficial for students' learning achievement, especially in text-based activities such as essay writing (Kim, 2012).

\section{Virtualization-Based Laboratory}

Lahoud and Tang (2006) as well as Summers, Bhagyavati, and Martin (2005) have suggested using on-campus, remote-access laboratory facilities. In this manner, learners can access work on real devices and monitor the results achieved on the system. 
Recently, this type of remote-access laboratory has been adopted in various computer science courses. However, one disadvantage of this type of laboratory is that it requires a properly installed laboratory facility and additional resources to handle such remote access. Moreover, reconfiguring this type of laboratory requires significant effort from numerous staff members (Abler, Contis, Grizzard, \& Owen, 2006).

In related work, Duarte, Butz, Miller, and Mahalingam (2008) proposed using a software simulator within an engineering laboratory. Software simulators include graphical user interfaces (GUIs) that provide learners with a more realistic and enhanced learning experience. The simulator design and its static components (text, pictures, etc.) have proven to be extremely effective for improving the learning capabilities of students. According to recent research, these simulators are designed to emulate hardware laboratory tools and they can easily adapt to certain situations. Additionally, virtual web-based laboratories can interface with software simulators and other software systems (Nieh \& Vaill, 2005; Sarkar \& Lian, 2003). Furthermore, implementing a laboratory with software simulation can be cost efficient since a simulator can be easily interoperated, especially when coding open-source software. However, one disadvantage of these simulators is that they cannot be implemented to cover all aspects of real laboratory equipment.

As stated earlier, Anisetti et al. (2007), Border (2007), and Wannous and Nakano (2010) introduced virtualization-based technology as a new way of installing a group of VMs on one server and running OSs on these VMs. Moreover, laboratories that implement virtualization-based technology allow learners to conduct experiments on real laboratory devices with flexible and portable features that have been successfully tested and verified for learning purposes. Recently, this virtualization-based laboratory has even been utilized in cloud computing (Chengjun, Quanhong, \&Heng, 2012).

\section{Virtualization Technology in Education}

In 2007, IBM published Virtualization in Education, which concluded that a virtual computer is a logical representation of a computer in software. By decoupling the physical hardware from the OS, virtualization provides more operational flexibility and increases the utilization rate of the underlying physical hardware. This concept can be applied to devices, servers, OSs, applications, and even networks. Virtualization also has a significant impact on education technology in two major areas. The first area is operational efficiency and related costs, and the second is the academic benefit of improved student performance from allowing student-owned devices to connect to the network. 


\section{Method}

\section{Participants and Procedures}

The experiment was conducted during the summer semester (March to May 2013) at Kasetsart University Chalermphrakiat Sakon Nakhon Province Campus, Thailand. The participants in this experiment consisted of a total of 35 undergraduate students enrolled in two sections of an Information Technology and Computer Science (ITCS) class. One section with 15 students served as the control group while the other section with 20 students served as the experimental group.

The procedures of this experiment were based on four overall steps, as shown in Figure 1: 1) pre-test 1 and laboratory orientation; 2) experimental treatment and post-test 1 for the Basic Labs; 3) pre-test 2 and experimental treatment for the Advanced Labs; and 4) post-test 2 and a questionnaire. The experiment was administered twice a week in three-hour increments. The same teacher lectured both groups with the same laboratory topics (Appendix B), which consisted of two parts: Basic Labs (Linux concept and basic practices [Labs 1-3]) and Advanced Labs (Linux networking and advanced practices [Labs 4-6]). In the laboratory class, the experimental group conducted their laboratory assignments using NVBLab, while the control group performed them on VMs that were installed on their PCs. In the initial class, the teacher informed the experimental group about how to use NVBLab. In addition, the experimental group was encouraged to use NVBLab to complete the laboratory and homework assignments as well as to identify the strengths and limitations of NVBLab.

\section{Learning Activity Designs}

This experiment included learning activities consisting of individual and group assignments, which were designed on the basis of laboratory topics and network equipment. For example, the topics of the Basic Labs and the Advanced Labs were assigned as individual and group activities, respectively. However, since the network equipment of the control group could not support group activity, the Advanced Labs' assignments for this group were created as individual ones. On the other hand, the NVBLab of the experimental group could be utilized to support group assignments, thus this group could have group activities. Details regarding the designed laboratory class and the homework assignments are described as follows.

Group laboratory assignment: The group laboratory assignments consisted of Advanced Labs for the experimental students. The students were divided into groups of five and asked to collaborate with their fellow group members to complete the laboratory assignments within the class period. Again, the experimental students had OSDs with the teacher, TA, and group members using NVBLab's chat feature. In Lab 4, each experimental student configured a file server, a web server, a database server, a print server, and a FTP server. At the beginning of the assignment, one student 
configured one type of server and then explained how to configure the server to the other group members. In Labs 5 and 6, each experimental student managed and configured one of the five routers.

Individual laboratory assignment: The individual laboratory assignments consisted of Basic Labs for the experimental students and both Basic and Advanced Labs for the control students. The teacher and TA prepared the laboratory materials and assignments for both student groups. In the beginning of class, the teacher briefed the students about the objective and contents of the experiment and gave the assignments to the students, which were completed by the end of the three-hour class period. The completed assignments were then presented to the teacher and TA for evaluation. In Lab 4 (as shown in Appendix B), each control student configured a file server, a web server, a database server, a print server, and a FTP server, while in Labs 5-6 (as shown in Appendix B), each control student managed and configured three routers. In addition, the control students had face-to-face discussions with the teacher, TA, and classmates. Alternatively, the experimental students had OSDs with the teacher, TA, and their classmates using NVBLab's chat feature.

Homework: The teacher prepared the same homework assignments for the control group and the experimental group, which consisted of a post-laboratory question aimed at improving the students' understanding of the experiment. The experimental students were allowed to use NVBLab to determine the answers from the command manual window and redo the assignments to confirm their answers.

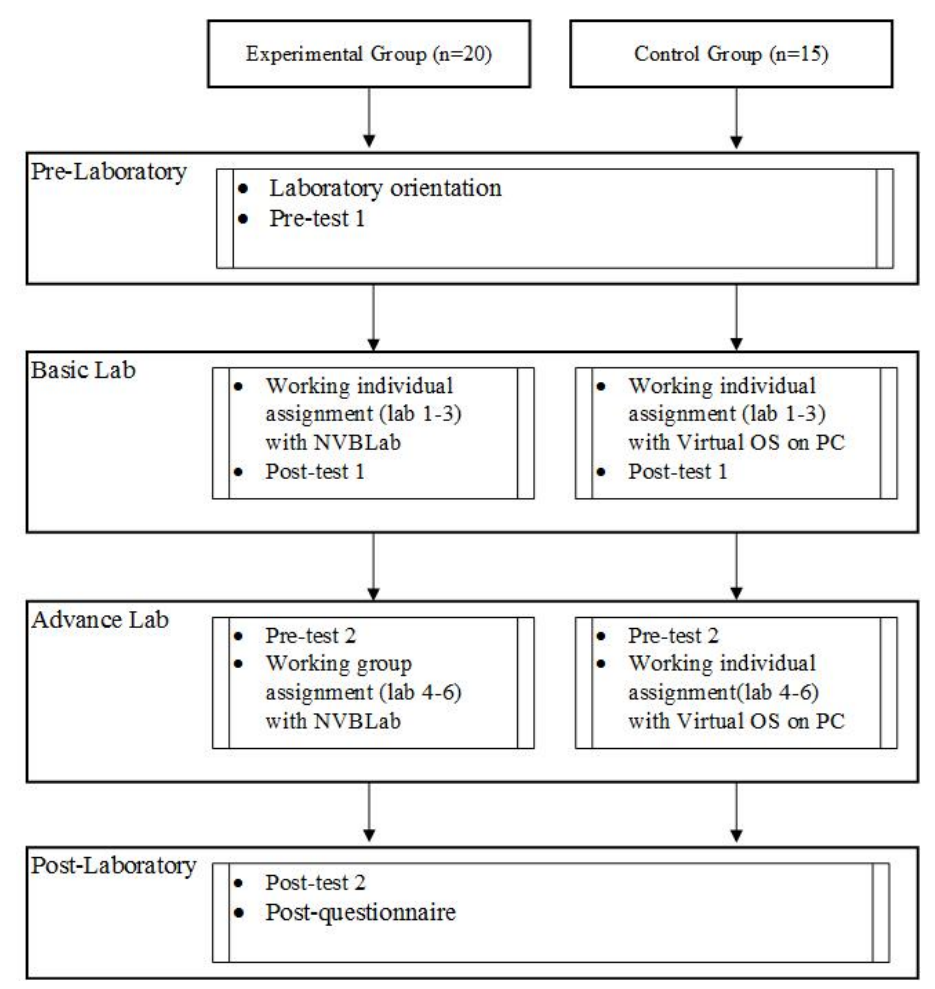

Figure 1. Flow chart for the experiment. 


\section{Research Variables}

In this experiment, the following variables related to command count, chat message count, homework scores, pre-test, and post-test were defined. In addition, a comparison of these variables was made between one another as well as with overall learning achievement.

1. Command count: The total number of Linux commands coded by a student using NVBLab for Labs 1-2 and 4-6.

2. Chat message count: The total number of chat messages typed by a student using NVBLab for Labs 1-2 and 4-6 that were relevant to the laboratory assignment.

3. Homework scores: The homework scores for Labs 1-6.

4. Pre-test and post-test: Pre-tests 1 and 2 are the students' exam scores before the Basic Labs and Advanced Labs, respectively. Post-test 1 is the students' midterm exam scores while Post-test 2 is the students' final exam scores.

\section{Research Questions}

1. What are the students' perceptions and behavioral intentions when using NVBLab in the computer networking laboratory?

2. When using NVBLab, do the students perform their assignments (homework and post-test objectives) better than those who do not use NVBLab?

3. How were the collaborative activities of NVBLab beneficial to students' learning and what reasons were deduced from the interviews?

\section{A Networking Virtualization-Based Laboratory: NVBLab}

The structure of NVBLab includes: a group of guest OSs on one host; a guest OS that operates as a network device; and an administrator who manages NVBLab via remote access called Virtual-management. A diagram of the system structure is shown in Figure 2. 


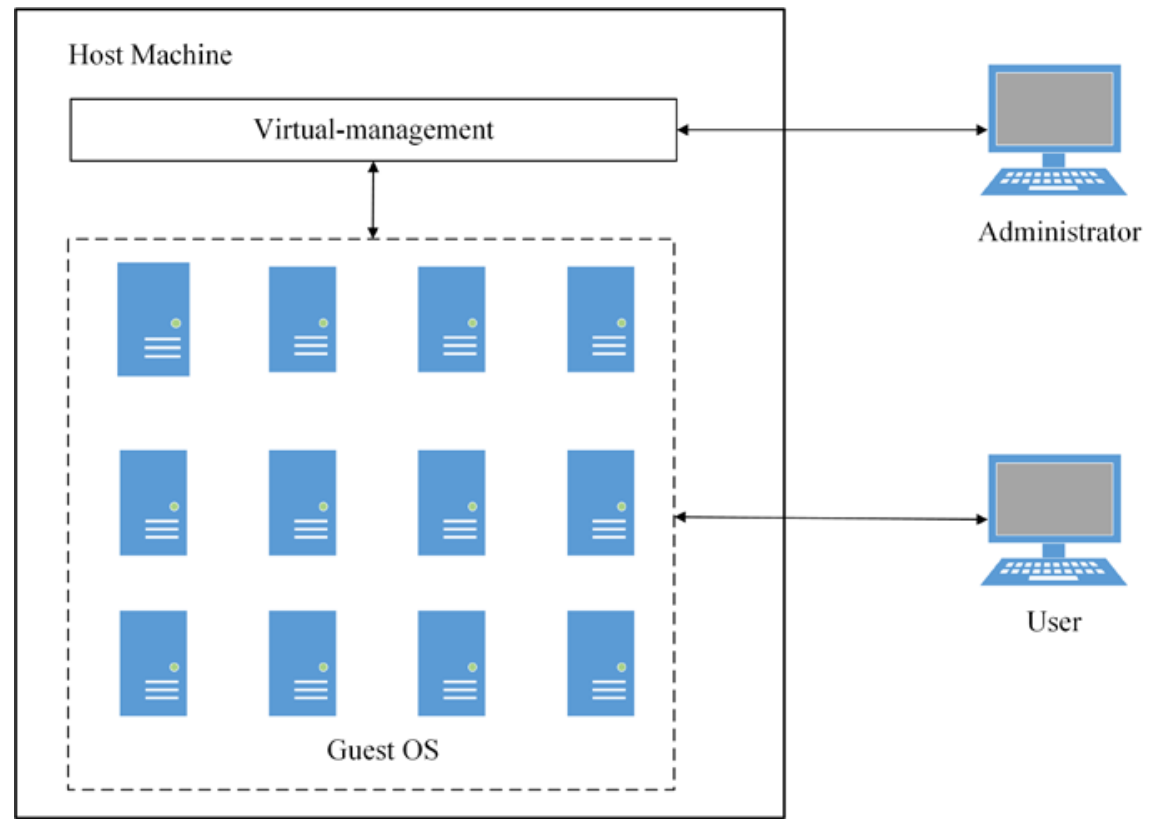

Figure 2. NVBLab structure.

Figure 3 shows that the web GUI is a simple server-side script with a GUI interface that includes the following: 1) a web Linux terminal that allows students to open a command line window on the guest OS; 2) a command search box that enables students to find the command manual; 3) laboratory materials for Labs 1-6; and 4), 5) a chat feature that allows students to have OSDs for sharing Linux and configuration commands with their class members. 


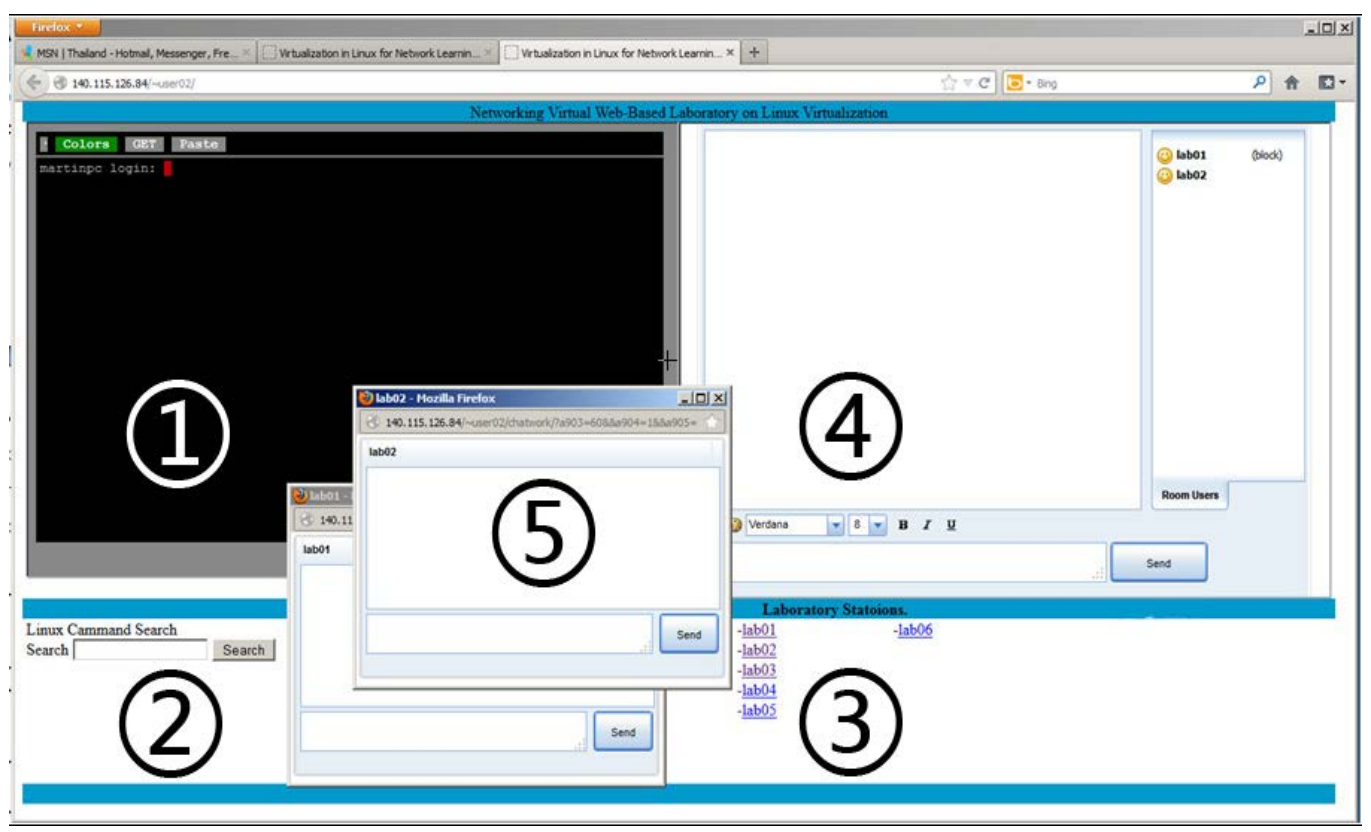

Figure 3. NVBLab Web GUI: 1) Web-terminal; 2) command search window; 3) laboratory materials; and 4), 5) group chat window and individual chat window.

\section{Results and Discussion}

The results of this research and the pedagogical implications are presented in relation to each research question above.

\section{Students' Perceptions and Behavioral Intentions}

A questionnaire survey was conducted in order to investigate the students' perceptions and behavioral intentions. The questionnaire was designed following the technology acceptance model (TAM) (Davis, 1986) and was based on the following four dimensions: 1) perceived ease of NVBLab use; 2) perceived usefulness of NVBLab; 3) attitude toward using NVBLab; and 4) behavioral intentions when using NVBLab. Furthermore, it included five additional dimensions: 1) system characteristics of NVBLab; 2) system accessibility of NVBLab; 3) perceived readiness from using NVBLab; 4) perceived usefulness of NVBLab for collaborative group work; and 5) perceived subjective norm from classmates to use NVBLab. Excluding questions regarding perceived usefulness of NVBLab for collaborative group work and questions number one and two of perceived usefulness of NVBLab for the control group, the responses obtained from the experimental and control groups were ranked using a five-point Likert scale (ranging from strongly disagree $=1$ to strongly agree $=5$ ). The statistical results of the questionnaire survey are presented in Tables 1-9 in Appendix A. According to the t-test results, the average mean scores of all the dimensions for the experimental group were higher than 
those for the control group. In addition, there were two statistically significant differences regarding system characteristics of NVBLab $(\mathrm{t}=2.896, \mathrm{p}=0.007)$ between the experimental group $(\mathrm{M}=4.67, \mathrm{SD}=0.568)$ and the control group $(\mathrm{M}=3.778, \mathrm{SD}=0.3)$ and system accessibility of NVBLab $(\mathrm{t}=3.267, \mathrm{p}=0.878)$ between the experimental group $(\mathrm{M}=3.967, \mathrm{SD}=0.878)$ and the control group $(\mathrm{M}=3.267, \mathrm{SD}=0.838)$. This finding demonstrates three aspects of the experiment. First, the experimental students perceived that they were better prepared for performing laboratory assignments when using NVBLab and it included good characteristics. Second, the students in the experimental group perceived that NVBLab provided a Linux OS environment that was more user-friendly than a real networking device. Third, the experimental students confirmed that NVBLab was easy to access and it offered quick and stable remote access. Moreover, the first four questionnaire dimensions were rated strongly agree and the additional five questionnaire dimensions were rated agree by the experimental group, and all of the questionnaire ratings of this group were higher than those of the control group. This indicates that NVBLab was ready to be utilized for this particular teaching computer network; NVBLab was uncomplicated and useful for conducting experiments and collaborative group work; and there was a subjective norm among the students for using and continuing to use NVBLab in their future studies.

In conclusion, the majority of the questionnaire dimensions were rated either strongly agree or agree, and there were statistically significant differences in the system characteristics of NVBLab and system accessibility of NVBLab dimensions. These results strongly imply that system characteristics and accessibility of NVBLab allow students to have real experiences of laboratory practices through this virtual device (Anisetti et al., 2007; Border, 2007; Wannous \& Nakano, 2010). Furthermore, the collaborative learning environment of NVBLab enhanced the experimental group's perceived collaboration during the laboratory class (McAlpine, 2006).

\section{T-Test Results of the Pre-Test, Post-Test, and Homework Scores}

Pre-test 1 shows no statistically significant difference $(t=0.14, \mathrm{p}=0.889)$ between the experimental group $(\mathrm{M}=3.95, \mathrm{SD}=1.76)$ and the control group $(\mathrm{M}=3.87, \mathrm{SD}=1.68)$ (see Table 1). In addition, Pre-test 2 shows no statistically significant difference $(t=-0.418$, $\mathrm{p}=.679)$ between the experimental group $(\mathrm{M}=2.10, \mathrm{SD}=0.72)$ and the control group ( $\mathrm{M}$ $=2.20$, SD $=0.68$ ). This indicates that these two groups possessed similar background skills in both the Basic and Advanced Labs.

Next, the analysis of Post-test 1 shows no statistically significant difference $(t=0.414, p=$ $0.681)$ between the experimental group $(\mathrm{M}=19.15, \mathrm{SD}=3.86)$ and the control group $(\mathrm{M}=$ 18.60, $\mathrm{SD}=3.92$ ). However, the analysis of Post-test 2 shows a statistically significant difference $(t=2.289, p=0.033)$ between the experimental group $(\mathrm{M}=12.15, \mathrm{SD}=2.11)$ and the control group $(\mathrm{M}=9.53, \mathrm{SD}=4.03)$. This suggests that NVBLab improved students' learning achievement in the Advanced Labs. 
In the Basic Labs, the experimental and control students performed the same individual assignments. Alternatively, in the Advanced Labs, the experimental students worked on group assignments while the control students worked on individual assignments. Since the experimental students participated in and had numerous discussions through chatting, Telnet, SSH, browsing, and group networking configurations, which are activities that tend to impart more knowledge than that gained through individual activities (Stahl, 2006), their learning achievement increased and they outperformed the control students.

Moreover, the results of the homework scores show statistically significant differences in Homework $5(\mathrm{t}=2.448 ; \mathrm{p}=0.023)$ between the experimental group $(\mathrm{M}=3.30, \mathrm{SD}=0.47)$ and the control group $(\mathrm{M}=2.73, \mathrm{SD}=0.80)$ and Homework $6(\mathrm{t}=2.462 ; \mathrm{p}=0.022)$ between the experimental group $(\mathrm{M}=3.2, \mathrm{SD}=0.52)$ and the control group $(\mathrm{M}=2.6, \mathrm{SD}$ $=0.83$ ). The results demonstrate that the experimental group improved their learning achievement more than the control group in the final two homework assignments. In addition, the experimental group was able to maintain homework scores that were higher than 3 points, whereas the homework scores of the control group dropped to less than 3 points. The primary reason for this difference is that the experimental students used NVBLab for collaborative work and support from their group members.

\section{T-Test Result of the Command Count}

There are statistically significant differences regarding command count in Lab 2 ( $\mathrm{t}=$ 6.369, $\mathrm{p}=0.00)$ between the experimental group $(\mathrm{M}=43.70, \mathrm{SD}=18.33)$ and the control group $(\mathrm{M}=15.40, \mathrm{SD}=6.653)$ and Lab $6(\mathrm{t}=3.033, \mathrm{p}=0.006)$ between the experimental group $(\mathrm{M}=71.35, \mathrm{SD}=10.18)$ and the control group $(\mathrm{M}=55.27, \mathrm{SD}=$ 18.545). The command count is not related to learning achievement, but it is an indicator of the students' attention. As seen in Table 1, the mean of the laboratory command count of the experimental group was higher than the mean for the control group. This implies that the experimental students did more activities in command practices than the control students. Moreover, the significant differences regarding command count in Labs 2 and 6 show that NVBLab influenced the experimental students to complete more assignments than the control students. 
Table 1

Results of the Assessment and T-Test

\begin{tabular}{|c|c|c|c|c|c|c|c|c|c|c|c|c|}
\hline \multirow[t]{2}{*}{ Assessment } & \multicolumn{3}{|c|}{$\begin{array}{l}\text { Control group } \\
(\mathrm{n}=15)\end{array}$} & \multicolumn{3}{|c|}{$\begin{array}{l}\text { Experimental } \\
\text { group } \\
(\mathrm{n}=20)\end{array}$} & \multirow[t]{2}{*}{$\mathrm{F}$} & \multirow[t]{2}{*}{ Sig. } & \multirow[t]{2}{*}{$\mathrm{t}$} & \multirow[t]{2}{*}{$\mathrm{df}$} & \multirow{2}{*}{$\begin{array}{l}\text { Sig. } \\
\text { (2- } \\
\text { tailed) }\end{array}$} & \multirow[t]{2}{*}{$\mathrm{MD}$} \\
\hline & Mean & SD & $\mathrm{SE}$ & Mean & SD & $\mathrm{SE}$ & & & & & & \\
\hline Pre-test 1 & 3.87 & 1.68 & 0.43 & 3.95 & 1.76 & 0.39 & $\begin{array}{l}0.10 \\
8\end{array}$ & $\begin{array}{l}0.74 \\
4\end{array}$ & 0.141 & 33 & 0.889 & 0.08 \\
\hline Pre-test 2 & 2.20 & 0.68 & 0.17 & 2.10 & 0.72 & 0.16 & $\begin{array}{l}0.0 \\
02\end{array}$ & $\begin{array}{l}0.96 \\
4\end{array}$ & $\begin{array}{l}-0.4 \\
18\end{array}$ & 33 & 0.679 & $\begin{array}{l}-0.1 \\
0\end{array}$ \\
\hline Post-test 1 & 18.60 & 3.92 & 1.01 & 19.15 & 3.86 & 0.86 & 0.09 & $\begin{array}{l}0.77 \\
3\end{array}$ & 0.414 & 33 & 0.681 & 0.55 \\
\hline Post-test 2 & 9.53 & 4.03 & 1.04 & 12.15 & 2.11 & 0.47 & $\begin{array}{l}15.5 \\
5\end{array}$ & $\begin{array}{l}0.0 \\
0\end{array}$ & $\begin{array}{l}2.28 \\
9\end{array}$ & 19.72 & $\begin{array}{l}0.033 \\
*\end{array}$ & 2.62 \\
\hline Homework 1 & 4.73 & 1.03 & 0.27 & 4.45 & 0.60 & 0.14 & $\begin{array}{l}0.06 \\
4\end{array}$ & $\begin{array}{l}0.8 \\
02\end{array}$ & $\begin{array}{l}-1.01 \\
9\end{array}$ & 33 & 0.316 & $\begin{array}{l}-0.2 \\
8\end{array}$ \\
\hline Homework 2 & 3.87 & 0.52 & 0.13 & 4.05 & 0.60 & 0.14 & $\begin{array}{l}0.14 \\
8\end{array}$ & $\begin{array}{l}0.70 \\
3\end{array}$ & $\begin{array}{l}0.94 \\
3\end{array}$ & 33 & 0.352 & 0.18 \\
\hline Homework 3 & 4.20 & 0.68 & 0.17 & 3.65 & $\begin{array}{l}0.8 \\
8\end{array}$ & 0.20 & $\begin{array}{l}1.56 \\
1\end{array}$ & 0.22 & $\begin{array}{l}-2.0 \\
21\end{array}$ & 33 & 0.051 & $\begin{array}{l}-0.5 \\
5\end{array}$ \\
\hline Homework 4 & 3.13 & 0.35 & 0.09 & 3.10 & 0.31 & 0.07 & $\begin{array}{l}0.35 \\
5\end{array}$ & $\begin{array}{l}0.55 \\
6\end{array}$ & $\begin{array}{l}-0.2 \\
98\end{array}$ & 33 & 0.767 & $\begin{array}{l}-0.0 \\
3\end{array}$ \\
\hline Homework 5 & 2.73 & $\begin{array}{l}0.8 \\
0\end{array}$ & 0.20 & 3.30 & 0.47 & 0.07 & 7.67 & $\begin{array}{l}0.0 \\
09\end{array}$ & $\begin{array}{l}2.44 \\
8\end{array}$ & 21.17 & $\begin{array}{l}0.023 \\
*\end{array}$ & 0.57 \\
\hline Homework 6 & 2.60 & 0.83 & 0.21 & 3.20 & 0.52 & 0.12 & $\begin{array}{l}7.57 \\
4\end{array}$ & 0.01 & 2.462 & 22.17 & $\begin{array}{l}0.022 \\
*\end{array}$ & 0.60 \\
\hline Lab 1 & 68.8 & 32.9 & 8.50 & 92.25 & 32.3 & 07.2 & 0.0 & 0.98 & 2.010 & 33 & 0.053 & 22.3 \\
\hline $\begin{array}{l}\text { Command } \\
\text { count }\end{array}$ & 7 & 5 & & & 5 & 3 & 00 & 2 & & & & 83 \\
\hline Lab 2 & 15.40 & 6.65 & 1.72 & 43.70 & 18.3 & 4.09 & 15.2 & 0.0 & 6.369 & 25.2 & 0.000 & 28.3 \\
\hline $\begin{array}{l}\text { Command } \\
\text { count }\end{array}$ & & 3 & & & 3 & 8 & 61 & 00 & & 0 & & \\
\hline $\begin{array}{l}\text { Lab } 4 \\
\text { Command } \\
\text { count }\end{array}$ & 85.47 & $\begin{array}{l}38.9 \\
2\end{array}$ & $\begin{array}{l}10.0 \\
5\end{array}$ & 107.3 & $\begin{array}{l}49.9 \\
3\end{array}$ & $\begin{array}{l}11.1 \\
6\end{array}$ & $\begin{array}{l}0.64 \\
1\end{array}$ & $\begin{array}{l}0.42 \\
9\end{array}$ & 1.402 & 33 & 0.17 & $\begin{array}{l}21.83 \\
3\end{array}$ \\
\hline Lab 5 & 68.27 & 36.0 & 9.30 & 85.5 & 33.1 & 7.42 & 0.01 & 0.90 & 1.466 & 33 & 0.152 & 17.23 \\
\hline $\begin{array}{l}\text { Command } \\
\text { count }\end{array}$ & & 47 & 7 & 0 & 6 & & 4 & 7 & & & & 3 \\
\hline $\begin{array}{l}\text { Lab } 6 \\
\text { Command }\end{array}$ & 55.27 & $\begin{array}{l}18.5 \\
45\end{array}$ & 4.79 & 71.35 & $\begin{array}{l}10.1 \\
8\end{array}$ & $\begin{array}{l}2.27 \\
7\end{array}$ & $\begin{array}{l}10.1 \\
15\end{array}$ & $\begin{array}{l}0.0 \\
03\end{array}$ & $\begin{array}{l}3.03 \\
3\end{array}$ & $\begin{array}{l}20.2 \\
84\end{array}$ & $\begin{array}{l}0.006 \\
*\end{array}$ & $\begin{array}{l}16.08 \\
3\end{array}$ \\
\hline
\end{tabular}

$$
* \mathrm{p}<0.05
$$


Table 2

Pearson Correlation Result Between the Post-Test, the Chat Message Count, and the Command Count $(\mathrm{n}=20)$

\begin{tabular}{|c|c|c|c|c|c|c|c|c|}
\hline & & $\begin{array}{l}\text { Command } \\
\text { count } 1\end{array}$ & $\begin{array}{l}\text { Command } \\
\text { count } 2\end{array}$ & $\begin{array}{l}\text { Command } \\
\text { count } 4\end{array}$ & $\begin{array}{l}\text { Command } \\
\text { count } 5\end{array}$ & $\begin{array}{l}\text { Command } \\
\text { count } 6\end{array}$ & $\begin{array}{l}\text { Post- } \\
\text { test } 1\end{array}$ & $\begin{array}{l}\text { Post- } \\
\text { test } 2\end{array}$ \\
\hline \multirow{2}{*}{$\begin{array}{l}\text { Chat } \\
\text { message } \\
\text { count } 1\end{array}$} & $\begin{array}{l}\text { Pearson } \\
\text { Correlation }\end{array}$ & -0.109 & -0.053 & 0.135 & 0.124 & 0.238 & $\begin{array}{l}0.49 \\
9 *\end{array}$ & 0.253 \\
\hline & Sig. (2-tailed) & 0.648 & 0.826 & 0.569 & 0.602 & 0.311 & $\begin{array}{l}0.02 \\
5\end{array}$ & 0.283 \\
\hline \multirow{2}{*}{$\begin{array}{l}\text { Chat } \\
\text { message } \\
\text { count } 2\end{array}$} & $\begin{array}{l}\text { Pearson } \\
\text { Correlation }\end{array}$ & 0.254 & 0.190 & 0.189 & 0.156 & 0.337 & $\begin{array}{l}0.65 \\
7 * *\end{array}$ & $0.466^{*}$ \\
\hline & Sig. (2-tailed) & 0.279 & 0.422 & 0.426 & 0.510 & 0.146 & $\begin{array}{l}0.00 \\
2\end{array}$ & 0.038 \\
\hline \multirow{2}{*}{$\begin{array}{l}\text { Chat } \\
\text { message } \\
\text { count } 4\end{array}$} & $\begin{array}{l}\text { Pearson } \\
\text { Correlation }\end{array}$ & -0.206 & -0.371 & -0.100 & -0.130 & -0.120 & $\begin{array}{l}0.02 \\
3\end{array}$ & $\begin{array}{l}-0.05 \\
5\end{array}$ \\
\hline & Sig. (2-tailed) & 0.384 & 0.107 & 0.674 & 0.585 & 0.616 & $\begin{array}{l}0.92 \\
2\end{array}$ & 0.818 \\
\hline \multirow{2}{*}{$\begin{array}{l}\text { Chat } \\
\text { message } \\
\text { count } 5\end{array}$} & $\begin{array}{l}\text { Pearson } \\
\text { Correlation }\end{array}$ & -0.156 & 0.119 & 0.068 & $0.526^{*}$ & $0.532^{*}$ & $\begin{array}{l}0.40 \\
8\end{array}$ & $\begin{array}{l}0.622 * \\
*\end{array}$ \\
\hline & Sig. (2-tailed) & 0.511 & 0.618 & 0.776 & 0.017 & 0.016 & $\begin{array}{l}0.07 \\
4\end{array}$ & 0.003 \\
\hline \multirow{2}{*}{$\begin{array}{l}\text { Chat } \\
\text { message } \\
\text { count } 6\end{array}$} & $\begin{array}{l}\text { Pearson } \\
\text { Correlation }\end{array}$ & -0.066 & 0.267 & -0.070 & $0.453^{*}$ & $0.532^{*}$ & $\begin{array}{l}0.28 \\
7\end{array}$ & $0.468^{*}$ \\
\hline & Sig. (2-tailed) & 0.781 & 0.255 & 0.768 & 0.045 & 0.016 & $\begin{array}{l}0.22 \\
0\end{array}$ & 0.038 \\
\hline \multirow[t]{2}{*}{ Post-test 1} & $\begin{array}{l}\text { Pearson } \\
\text { Correlation }\end{array}$ & 0.268 & 0.359 & 0.345 & 0.380 & $0.483^{*}$ & & \\
\hline & Sig. (2-tailed) & 0.253 & 0.120 & 0.137 & 0.098 & 0.031 & & \\
\hline Post-test 2 & $\begin{array}{l}\text { Pearson } \\
\text { Correlation }\end{array}$ & 0.001 & 0.227 & 0.176 & $0.562^{* *}$ & $0.558^{*}$ & & \\
\hline$* p<0.05$ & $\begin{array}{l}\text { Sig. (2-tailed) } \\
; * * \mathrm{p}<0.01\end{array}$ & 0.998 & 0.335 & 0.457 & 0.010 & 0.011 & & \\
\hline
\end{tabular}

\section{Pearson Correlation Analysis Between the Post-Test, the Chat Message Count, and the Command Count}

The results of the Pearson correlation analysis show a significant correlation between the chat message count and the post-test in Lab 1 ( $r=0.499, \mathrm{p}=0.025) ; 2(\mathrm{r}=0.657, \mathrm{p}$ $=0.002) ; 5(r=0.622, p=0.003)$; and $6(r=0.468, p=0.038)$, the post-test and the command count in Lab 5 ( $r=0.562, p=0.01)$ and $6(r=0.558, p=0.011)$, and the command count and chat message count in Lab $5(r=0.526, p=0.017)$ and $6(r=0.532$, $\mathrm{p}=0.016$ ). Firstly, the significant correlations between the post-test and chat message count in Labs 1, 2, 5, and 6 show that OSDs can be beneficial for students' learning performance, especially in text-based activities (Hou, Chang, \& Sung, 2008; Kim, 2012). The experimental students, when inputting Linux commands, usually worked in both 
the web terminal and the chat message window. As a result, they received immediate feedback and support from other class members. Secondly, the significant correlations between the post-test and the command count in Labs 5 and 6 show that when the experimental students do more activities in the same assignments with control students in the Advanced Labs, they increase their learning performance. Finally, there were significant correlations between the command count and the chat message count in Labs 5 and 6 . These indicate that the experimental students actively collaborate to do these two laboratory assignments that are caused by OSD providing a useful communication to exchange understanding. As a consequence, they get more command count (Holliman \& Scanlon, 2006). In addition, in Labs 5 and 6, both chat message and command count positively and significantly influence the achievement. Therefore, the experimental students complete more assignments and have more interaction like chatting and using command, and they can get a higher level of learning achievement.

\section{Interview and In-Depth Investigation}

During the one-on-one semi-structured interviews, the students mentioned that they could benefit from using NVBLab for experiments in class as well as homework. Regarding the use of NVBLab for experiments, the students pointed out a technical issue in which the virtualization OS was defective due to student error or unstable OS software. Since this occurred occasionally throughout the experiment, the students had to change to another virtualization OS in order to complete the assignment (Nieh \& Vaill, 2005). The following content was extracted from two different interviews:

In Lab 3, I installed Linux OS several times but the OS did not run. Therefore, I could not finish the lab assignment on time. After the teacher allowed me to use NVBLab, I was able to continue the assignment and finish it 30 minutes after the class period.

Due to problems with the Linux configuration, I performed some configurations by following the lab sheets, but I still could not complete the assignments. Moreover, other group members helped me with the configurations but it still did not work. Finally, after the TA created a new Linux OS in NVBLab, I was able to finish the assignment on time.

In addition, students preferred conducting the experiment by chatting with other group members in NVBLab. The reason for such behavior was that the students wanted to determine the correct network configuration and commands with their class members. Therefore, the teacher guided the students to utilize the chat feature and the students were able to easily follow the teacher to complete the experiment (Mason, 1991; Muirhead, 2000). Moreover, the students also mentioned that NVBLab and the webbased terminal was easy to use. The following content is derived from two different interviews: 
During the laboratory class, I often used NVBLab to chat with other group members, the TA and the teacher. I obtained the IP numbers from my group members because it was difficult to remember them from our conversation since there were so many to configure for the assignment.

I always received extra commands that were not included on the lab sheets. This was very helpful for me and my group members. I could just copy and paste the data directly from my chat window. For the lab assignments, we were required to create a new network design. So the teacher and TA guided us by sending the correct commands.

Regarding the use of NVBLab's command search window, the students queried Linux commands in the window in order to construct commands and special networking configurations such as long commands, special IPs, and router commands. The following content is extracted from two different interviews:

NVBLab gave me a Linux command description in the Thai language, which was very helpful for me. In this way, I no longer need to find the command comparisons in the Linux manual that have long command descriptions in English.

During the network configuration part of the lab, there was no routing command in the Linux manual. However, NVBLab's command search window gave us a clear command description. The teacher and TA then prepared the suitable routing command description for us to apply.

\section{Implications Regarding Education and Technology}

Based on the findings, this study presents the following implications and recommendations for educators who plan to teach in a Linux networking virtualizationbased laboratory. Firstly, it recommends using NVBLab to enhance students' understanding of laboratory content as well as applying such technology both during and after the lectures. Secondly, NVBLab is a collaborative learning environment in which educators and students can have direct and immediate conversations via a chat feature. In addition, educators can simultaneously monitor students in class and help them correct certain configurations by sending messages. Therefore, this collaborative chat feature increases students' attention to perform assignments during laboratory class. Thirdly, since the students' behaviors during the Basic and Advanced Labs differed when working on the assignments, educators need to communicate more via 
online discussions during the Basic Labs, especially since students are generally unfamiliar with new procedures. Alternatively, in the Advanced Labs (group assignments), the students had many discussions with their group members. Thus, educators should use online discussions to communicate with their class via the chat feature, especially for giving guideline commands. Fourthly, this experiment recommends that educators prepare and evaluate the lab sheets for their students in order to ensure that they are correct. In this regard, incorrect lab sheets can prevent students from completing the assignments within the class period, which can affect their acceptance of the proposed system. This is especially important during the Advanced Labs.

Finally, this experiment shows that NVBLab can be a cost-efficient laboratory solution compared to the cost of buying high-profile networking equipment directly from the manufacturers. However, the number of guest OSs which will install in the host machine is limited; it depends on the host capability. Previous research allowed one user to work on the virtualization laboratory to do one assignment at one time (Abler, Contis, Grizzard, \& Owen, 2006; Wannous \& Nakano, 2010). Conversely, in this research study we allowed all students to work during the same time period because we assigned each student with one guest OS. After that the guest OS of each student could connect to the guest OS of other group members to establish a networking topology of collaborative assignments and to have discussions. Furthermore, if educators apply the Linux OS to teach networking, then students will gain experience both in networking and Linux (Unix-based), which is currently the most popular OS for Android, IOS, and Mac OS, thus providing students with the basis to further obtain much sought-after skill sets.

\section{Conclusion}

This experiment applied NVBLab with OSD capabilities for a computer networking laboratory class in order to determine its effectiveness on learning performance. In addition, it investigated the students' perceptions and behavioral intentions when using NVBLab. First of all, it successfully deployed a virtualization technique into a computer networking laboratory class. This technique allowed the instructor to create a variety of virtual networking topologies for laboratory class. Therefore, the students can learn with real networking experience. The students accepted NVBLab for performing the assignments during and after class. In addition, NVBLab was especially beneficial for group assignments since the OSD feature allowed the students to interact and share knowledge with other group members as well as the teacher and TA. Based on the findings, the OSD feature was a key factor for helping students complete the laboratory tasks within the class period. Overall, this virtualization technique proved to be an optimal method for virtual networking laboratory infrastructure.

There are several limitations that need to be acknowledged regarding this experiment. The first limitation is the relatively small sample size, which limits the broad 
generalization of the results. Therefore, in the future, this study will increase the sample size in both the control and experimental groups. Another limitation is the adoption of NVBLab by the teacher and TA, which requires additional time to prepare the system before or after class. Finally, for future development, efforts should include adding other types of tablet compatibility and screen sharing as well as a time recording and logging system. 


\section{References}

Abler, R. T., Contis, D., Grizzard, J . B., \& Owen, H. L. (2006). Georgia tech information security center hands-on network security laboratory. Education, IEEE Transactions, 49(1), 82-87.

Anisetti, M., Bellandi, V., Colombo, A., Cremonini, M., Damiani, E., Frati, F., . . . Rebeccani, D. (2007). Learning computer networking on open paravirtual laboratories. Education, IEEE Transactions, 50(4), 302-311.

Border, C. (2007). The development and deployment of a multi-user, remote access virtualization system for networking, security, and system administration classes. SIGCSE Bull., 39(1), 576-580.

Chengjun, X., Quanhong, T., \&Heng, Z. (2012, 14-17J uly 2012). A research of safety mechanism in cloud computing platform based on virtualization. Paper presented at the Computer Science \& Education (ICCSE), 2012 7th International Conference.

Davis, Jr, F. D. (1986). A technology acceptance model for empirically testing new enduser information systems: Theory and results. Massachusetts Institute of Technology.

Duarte, M., Butz, B. P., Miller, S. M., \& Mahalingam, A. (2008). An intelligent universal virtual laboratory (UVL). Education, IEEE Transactions, 51(1), 2-9.

Harasim, L. (2011). Learning theory and online technologies. Routledge.

Hew, K. F., \& Cheung, W. S. (2003). Evaluating the participation and quality of thinking of pre-service teachers in an asynchronous online discussion environment: Part 1. International J ournal of Instructional Media, 30(3), 247-262.

Holliman, R., \& Scanlon, E. (2006). Investigating cooperation and collaboration in near synchronous computer mediated conferences. Computers \&Education, 46(3), 322-335.

Hou, H.-T., Chang, K.-E., \& Sung, Y.-T. (2008). Analysis of problem-solving-based online asynchronous discussion pattern. Educational Technology \& Society, 11(1), 17-28.

IBM. (2007). Virtualization in education. IBM Global Education White Paper.

Retrieved from http://www-

07.ibm.com/ solutions/in/ education/download/Virtualization\%20in\%20Educat ion.pdf

Kehrwald, B. (2008). Understanding social presence in textbased online learning environments. Distance Education, 29(1), 89-106. 
Kim, I.-H. (2012). Development of reasoning skills through participation in collaborative synchronous online discussions. Interactive Learning Environments (ahead-of-print), 1-18.

Kimball, L. (1998). Managing distance learning - New challenges for faculty. In R. Hazemi, S. Hailes \& S. Wilbur (Eds.), The digital university (pp. 25-38). Springer London.

Lahoud, H. A., \&Xin Tang, P. (2006). Information security labs in IDS/ IPS for distance education. Paper presented at the Proceedings of the 7th conference on Information technology education, Minneapolis, Minnesota, USA.

Lobel, M., Swedburg, R., \& Neubauer, M. (2002). The eClassroom used as a teacher's training laboratory to measure the impact of group facilitation on attending, participation, interaction, and involvement. The International Review of Research in Open and Distance Learning, 3(2).

Mason, R. (1991). Analyzing computer conferencing interaction. International J ournal of Computers in Adult Education and Training, 2(3), 161-173.

McAlpine, I. (2000). Collaborative learning online. Distance Education, 21(1), 66-80.

Muirhead, B. (2000). Interactivity in a graduate distance education school. Educational Technology \& Society, 3(1), 2000.

Murphy, K. L., \& Collins, M. P. (1997). Communication conventions in instructional electronic chats. First Monday, 2(11).

Nieh, J ., \&Vaill, C. (2005). Experiences teaching operating systems using virtual platforms and linux. SIGCSE Bull., 37(1), 520-524.

Sarkar, N. I., \& Lian, J . H. (2003, 9-11J uly 2003). LAN-designer: A software tool for teaching and learning LAN design. Paper presented at the Advanced Learning Technologies, 2003. Proceedings. The 3rd IEEE International Conference.

Shana, Z. (2009). Learning with technology: Using discussion forums to augment a traditional-style class. Educational Technology \& Society, 12(3), 214-228.

Stahl, G. (2006). Group cognition: Computer support for building collaborative knowledge. Acting with technology series. MIT Press.

Summers, W. C., Bhagyavati, \& Martin, C. (2005). Using a virtual lab to teach an online information assurance program. Paper presented at the Proceedings of the 2nd annual conference on Information security curriculum development, Kennesaw, Georgia. 
Wannous, M., \& Nakano, H. (2010). NVLab, a networking virtual web-based laboratory that implements virtualization and virtual network computing technologies. Learning Technologies, IEEE Transactions on, 3(2), 129-138.

Wannous, M., Nakano, H., Kita, T., \& Sugitani, K. (2007). A core system for a webbased virtual computer laboratory. Paper presented at the Proc. Eighth Int'1 Conf. Information Technology in Higher Education and Training.

Watabe, K., Hamalainen, M., \&Whinston, A. B. (1995). An internet based collaborative distance learning system: Codiless. Computers \& Education, 24(3), 141-155. 


\section{Appendix A}

\section{Questionnaire Survey}

Table 1 System Characteristics of NVBLab.

\begin{tabular}{|c|c|c|c|c|c|c|c|}
\hline$\#$ & Item & Group & Item Mean & Dimension Mean & SD & $\mathrm{t}$ & Sig. (2-tailed) \\
\hline \multirow[t]{2}{*}{1} & \multirow{2}{*}{$\begin{array}{l}\text { I think that the proposed system can } \\
\text { provide a real Linux networking } \\
\text { environment as a working in real } \\
\text { machine. }\end{array}$} & Experimental & 4.50 & 4.267 & 0.568 & \multirow[t]{2}{*}{2.896} & \multirow[t]{2}{*}{$0.007^{*}$} \\
\hline & & Control & 4.47 & 3.778 & 0.30 & & \\
\hline \multirow[t]{2}{*}{2} & \multirow{2}{*}{$\begin{array}{l}\text { I think that the proposed system have } \\
\text { good facilitates. }\end{array}$} & Experimental & 4.10 & \multirow{4}{*}{\multicolumn{4}{|c|}{$* \mathrm{p}<0.05$}} \\
\hline & & Control & 3.80 & & & & \\
\hline \multirow[t]{2}{*}{3} & \multirow{2}{*}{$\begin{array}{l}\text { I think that the proposed system have } \\
\text { helpful peer and tutor support. }\end{array}$} & Experimental & 4.20 & & & & \\
\hline & & Control & 4.33 & & & & \\
\hline
\end{tabular}

Table 2 System Accessibility of NVBLab.

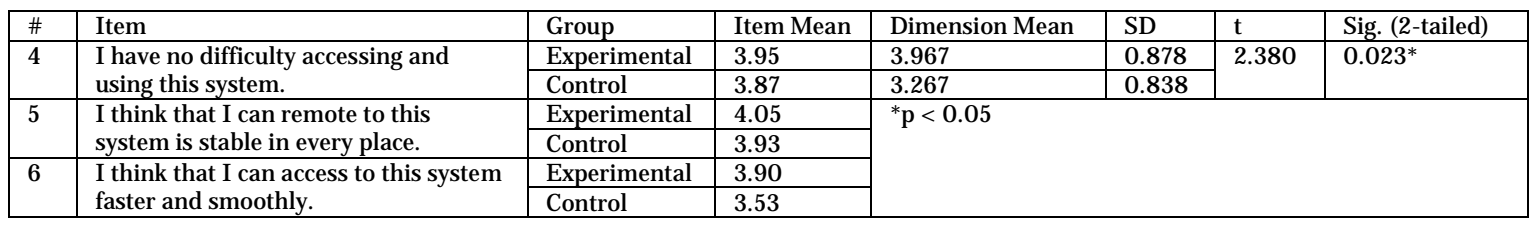

Table 3 Perceived Readiness from using NVBLab.

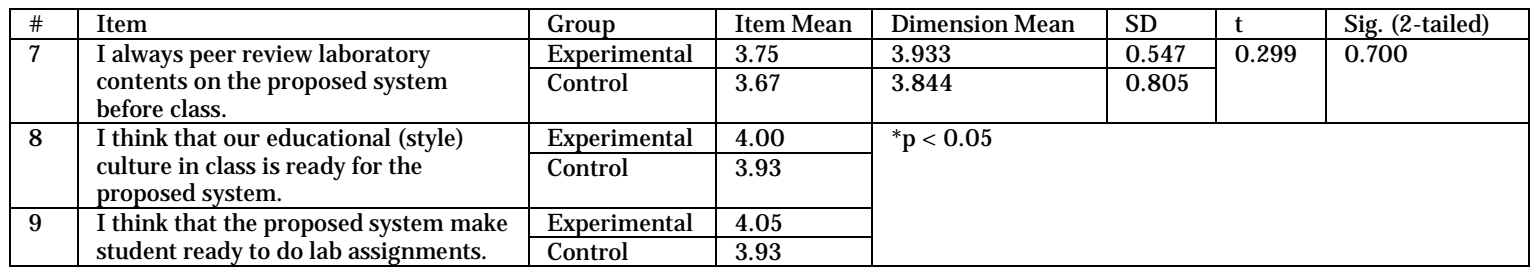

Table 4 Perceived Usefulness of NVBLab for Collaborative Group work.

\begin{tabular}{|c|c|c|c|c|c|c|c|}
\hline \# & Item & Group & Item Mean & Dimension Mean & SD & $\mathrm{t}$ & Sig. (2-tailed) \\
\hline \multirow[t]{2}{*}{10} & \multirow{2}{*}{$\begin{array}{l}\text { I would like to collaborate with class } \\
\text { mates in the same group for doing lab } \\
\text { assignments. }\end{array}$} & Experimental & 4.50 & 4.325 & 0.52 & \multirow[t]{2}{*}{-} & \multirow[t]{2}{*}{-} \\
\hline & & Control & - & - & - & & \\
\hline \multirow[t]{2}{*}{11} & \multirow{2}{*}{$\begin{array}{l}\text { I would like to collaborate with class } \\
\text { mates in another group for doing lab } \\
\text { assignments. }\end{array}$} & Experimental & 4.05 & \multirow[t]{6}{*}{$* \mathrm{p}<0.05$} & & & \\
\hline & & Control & - & & & & \\
\hline \multirow[t]{2}{*}{12} & \multirow{2}{*}{$\begin{array}{l}\text { I would like to share network } \\
\text { configuration and topology with group } \\
\text { members for doing lab assignments. }\end{array}$} & Experimental & 4.30 & & & & \\
\hline & & Control & - & & & & \\
\hline \multirow[t]{2}{*}{13} & \multirow{2}{*}{$\begin{array}{l}\text { From my experience, "collaboration" } \\
\text { among classmates usually succeeds to } \\
\text { finish assignment faster. }\end{array}$} & Experimental & 4.45 & & & & \\
\hline & & Control & - & & & & \\
\hline
\end{tabular}

Table 5 Perceived Subjective Norm from Classmates to Use NVBLab.

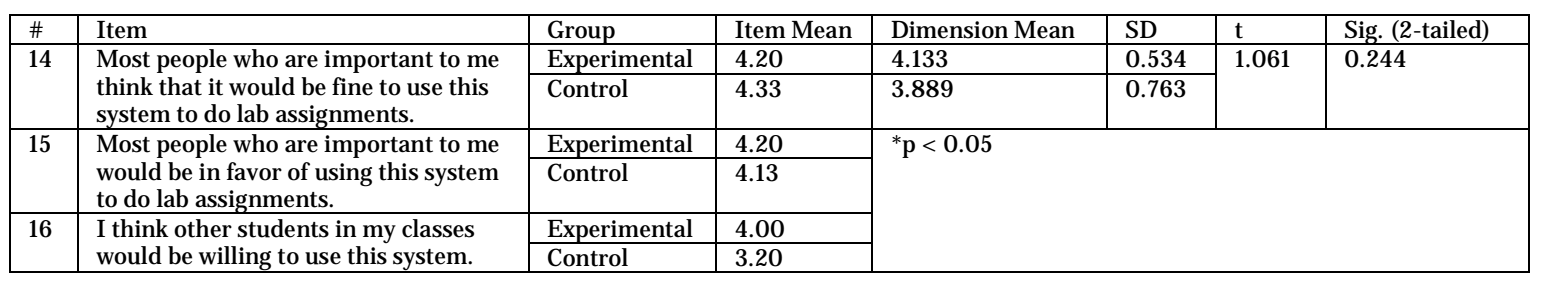


Table 6 Perceived Ease of NVBLab use.

\begin{tabular}{|c|c|c|c|c|c|c|c|}
\hline \# & Item & Group & Item Mean & Dimension Mean & SD & $\mathrm{t}$ & Sig. (2-tailed) \\
\hline \multirow[t]{2}{*}{17} & \multirow{2}{*}{$\begin{array}{l}\text { I think that the proposed system is very } \\
\text { convenient to do lab assignments. }\end{array}$} & Experimental & 4.05 & 3.850 & 0.455 & \multirow[t]{2}{*}{1.140} & \multirow[t]{2}{*}{0.268} \\
\hline & & Control & 4.00 & 3.567 & 0.879 & & \\
\hline \multirow[t]{2}{*}{18} & \multirow{2}{*}{$\begin{array}{l}\text { I think that the operation of the } \\
\text { proposed system does not require too } \\
\text { much time. }\end{array}$} & Experimental & 4.05 & \multirow[t]{6}{*}{$* p<0.05$} & & & \\
\hline & & Control & 3.93 & & & & \\
\hline \multirow[t]{2}{*}{19} & \multirow{2}{*}{$\begin{array}{l}\text { I think that the proposed system is } \\
\text { very easy to do practical lessons and } \\
\text { exercises after class. }\end{array}$} & Experimental & 3.80 & & & & \\
\hline & & Control & 3.73 & & & & \\
\hline \multirow[t]{2}{*}{20} & \multirow{2}{*}{$\begin{array}{l}\text { I feel that learning to use this system } \\
\text { is quite easy. }\end{array}$} & Experimental & 3.60 & & & & \\
\hline & & Control & 2.60 & & & & \\
\hline
\end{tabular}

Table 7 Perceived Usefulness of NVBLab.

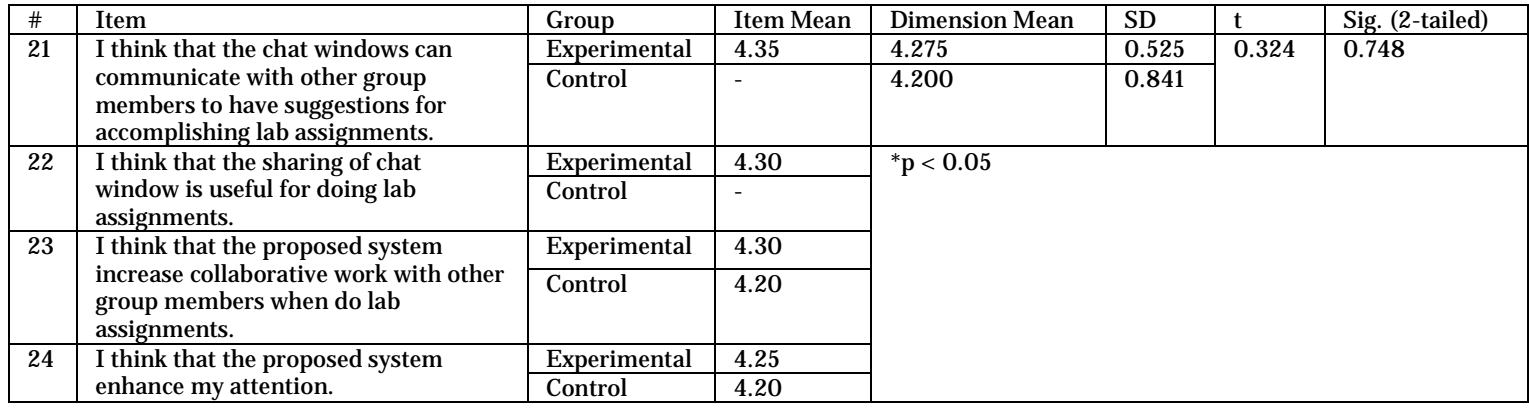

Table 8 Attitude toward using NVBLab.

\begin{tabular}{|c|c|c|c|c|c|c|c|}
\hline \# & Item & Group & Item Mean & Dimension Mean & SD & $\mathrm{t}$ & Sig. (2-tailed) \\
\hline \multirow[t]{2}{*}{25} & \multirow{2}{*}{$\begin{array}{l}\text { I like using this system to learn } \\
\text { networking. }\end{array}$} & Experimental & 4.20 & 4.267 & 0.525 & \multirow{2}{*}{0.799} & \multirow{2}{*}{0.430} \\
\hline & & Control & 4.07 & 4.111 & 0.626 & & \\
\hline \multirow[t]{2}{*}{26} & \multirow{2}{*}{$\begin{array}{l}\text { I have a positive attitude toward using } \\
\text { this system. }\end{array}$} & Experimental & 4.20 & \multirow{4}{*}{\multicolumn{4}{|c|}{${ }^{*} p<0.05$}} \\
\hline & & Control & 4.13 & & & & \\
\hline \multirow[t]{2}{*}{27} & \multirow{2}{*}{$\begin{array}{l}\text { I feel that using this system to do lab } \\
\text { assignments is a good method. }\end{array}$} & Experimental & 4.40 & & & & \\
\hline & & Control & 4.14 & & & & \\
\hline
\end{tabular}

Table 9 Behavioral Intentions when using NVBLab.

\begin{tabular}{|c|c|c|c|c|c|c|c|}
\hline \# & Item & Group & Item Mean & Dimension Mean & SD & $\mathrm{t}$ & Sig. (2-tailed) \\
\hline \multirow[t]{2}{*}{25} & \multirow{2}{*}{$\begin{array}{l}\text { If I have access to this system, I will } \\
\text { use it to learn networking. }\end{array}$} & Experimental & 4.25 & 4.150 & 0.129 & \multirow[t]{2}{*}{1.391} & \multirow[t]{2}{*}{0.174} \\
\hline & & Control & 3.93 & 3.778 & 0.258 & & \\
\hline \multirow[t]{2}{*}{26} & If I do lab assignments, I will enjoy & Experimental & 4.30 & \multirow{4}{*}{\multicolumn{4}{|c|}{$*_{p}<0.05$}} \\
\hline & doing with this system. & Control & 4.13 & & & & \\
\hline \multirow[t]{2}{*}{27} & \multirow{2}{*}{$\begin{array}{l}\text { I think that I will use this system to } \\
\text { help me when I do my homework. }\end{array}$} & Experimental & 3.90 & & & & \\
\hline & & Control & 3.27 & & & & \\
\hline
\end{tabular}




\section{Appendix B}

\section{Topic of Laboratory Assignment}

\section{Basic Labs: Linux concepts and basic practices}

Lab1 Introduction to Linux and Linux command

Lab2 Linux Script

Lab3 Install Linux

Advance Labs: Linux networking and advance practices

Lab4 Linux Networking, Configuration

Lab5 Linux Networking, Static Routing

Lab6 Linux Networking, Dynamic Routing 


\section{Appendix C}

Network topology of Linux Networking, Configuration: Lab4

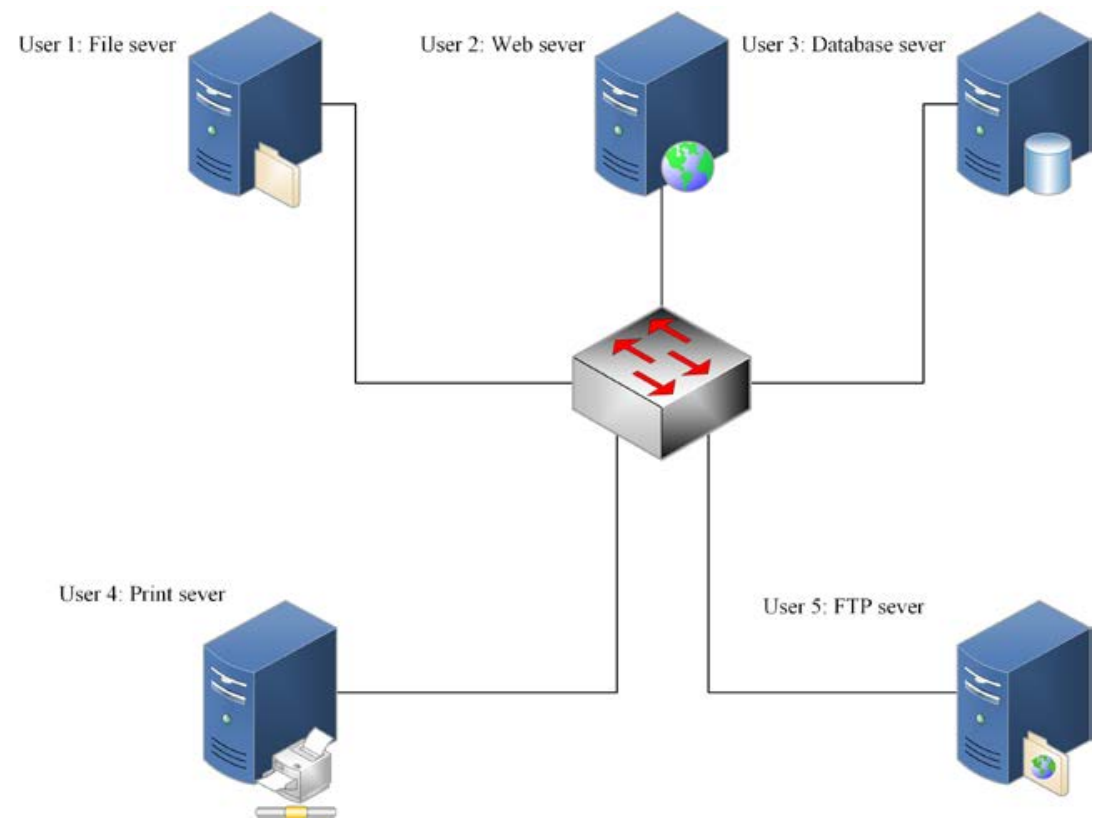




\section{Appendix D}

Network Topology of Networking, Static Routing, and Dynamic Routing: Lab5 and Lab6

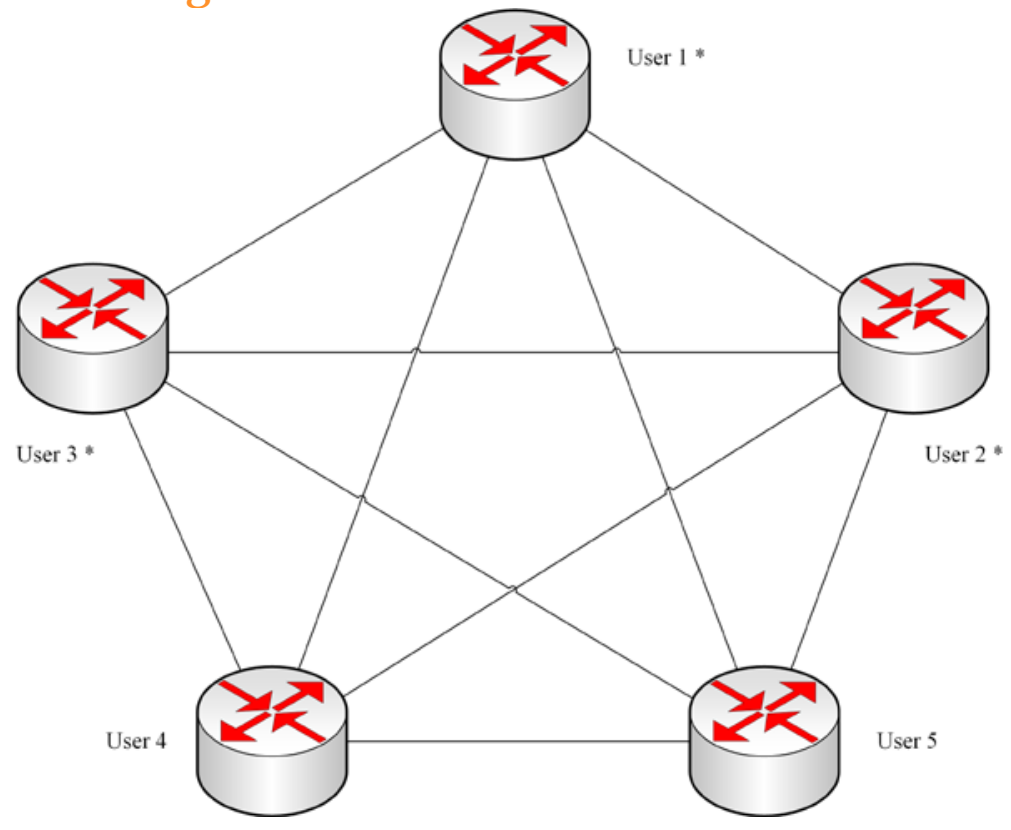

* The control group has to configure only 3 routers.

\section{Athabasca University $\mathbf{A}$}

(c)

